http://dx.doi.org/10.5007/1984-8420.2012v13n3p79

\title{
O ENSINO DA LÍNGUA BRASILEIRA DE SINAIS NA GRADUAÇÃO
}

\author{
LANGUAGE TEACHING IN GRADUATION SIGNS BRAZILIAN
}

Submetido em: 23-07-2012

Publicado em:23-02- 2013

Emiliana Faria Rosa

emilianarosa@gmail.com

Doutoranda do Programa de Pós-Graduação em Linguística - UFSC

\begin{abstract}
Resumo: Este trabalho visa levantar reflexões sobre o ensino da língua brasileira de sinais na graduação, uma vez que a disciplina de LIBRAS está inserida nesse contexto acadêmico em virtude do Decreto 5.626 de 22 de dezembro de 2005. Trata-se de um texto expositivo do cotidiano sobre o que acontece na sala de aula por meio das observações de quem leciona a referida disciplina. Deseja-se aqui expor fatos e características dessa inserção, levando em conta que a língua de sinais é uma língua de modalidade visuoespacial não conhecida por muitos dos participantes do meio acadêmico. Apesar das dificuldades apontadas no texto, nota-se que os professores tendem a criar possibilidades para superar as dificuldades e lecionar a disciplina, buscando encaminhamentos para que o ensino dessa língua seja incorporado nas universidades com qualidade.
\end{abstract}

Palavras-chave: LIBRAS. Ensino. Graduação.

Abstract: This work aims at raising reflections about Brazilian sign language (LIBRAS) teaching in undergraduate courses, since the school subject LIBRAS is inserted in this academic context due to Decreto 5.626 of 22nd. December 2005. This is a text that exposes what happens in the day to day life of classroom through the notes of the ones who teach the mentioned subject. It aims to approach facts and characteristics of this insertion taking into account that sign language is a language of visual-spatial modality which is not known by many people from acedemic medium. Despite the difficulties pointed in the text, it is noticeable that teachers tend to create possibilities to overcome these difficulties, teaching this school subject in such a way that makes it possible to incorporate sign language teaching in the universities with quality.

Key-words: Brazilian sign language. Teaching. Undergraduate courses.

\section{INTRODUÇÃO}

No cotidiano do professor de LIBRAS (língua brasileira de sinais) várias discussões sobre a presença, a interação e o ensino desta língua são notados. Tal cotidiano é vivenciado pela autora deste artigo como professora de língua de sinais em uma universidade e isso leva à necessidade de levantar questões ressaltadas buscando reflexões sobre o tema.

No ensino superior, observa-se a multiplicidade de línguas e suas variações linguísticas que se integram e ao mesmo tempo se diferenciam. São as línguas que

Work. pap. linguíst., 13(3): 79-86, Florianópolis, out.dez,2012 
movem o processo de ensino-aprendizagem. E, portanto, é impossível deixar a língua de sinais de fora dessa contextualização.

A existência de línguas além da língua portuguesa não é assunto novo no meio acadêmico. É por essa afirmação que se tem outra afirmação: a língua de sinais sempre foi conhecida, mas para ser reconhecida foi preciso a existência da lei. O Decreto 5.626 de 22 de dezembro de 2005, que regulamentou a LIBRAS, já reconhecida como uma das línguas oficiais no país desde a Lei n. ${ }^{\circ} 10.436$, de 24 de abril de 2002. A partir deste decreto, a língua de sinais integrou "oficialmente" o corpo linguístico do ensino superior, tanto como língua de uso comunicativo quanto como disciplina curricular.

$\mathrm{O}$ ensino de línguas estrangeiras além da língua portuguesa na universidade foi sempre presente no meio acadêmico, mas a LIBRAS, ou seja, Língua Brasileira de Sinais, é recente.

Após a oficialização da língua de sinais e da proposta de educação do Ministério da Educação e Cultura (MEC), conhecida como educação inclusiva, observou-se a criação da disciplina de língua de sinais no ensino superior, a fim de que os alunos da graduação (tanto licenciatura quanto bacharelado) obtivessem conhecimentos teóricos e práticos sobre o alunado surdo que poderiam encontrar, futuramente, em uma sala de aula. Sobre a educação inclusiva pode-se citar que:

A educação inclusiva configura-se como um movimento de intensa repercussão no âmbito das práticas educacionais, no trabalho pedagógico das escolas, porque desafia os sistemas, tensionando o campo educacional com muitas indagações e poucas afirmações. $\mathrm{O}$ que se tem de unânime é o direito público subjetivo à educação de qualquer criança, com ou sem deficiência. Nesse sentido, espera-se que o processo de inclusão exija profundas transformações das escolas. (GIORDANI, 2010, p.76)

Além de tudo isso há, presentemente, a inclusão social, levando a universidade a ser um dos locais no qual se preparam as pessoas para o que quer que aconteça. Embora isso seja por vezes utópico.

A LIBRAS aqui apresentada é a língua da comunidade surda brasileira que passou a ser reconhecida e oficializada com a existência da lei. O Decreto 5.626 de 22 de dezembro de 2005 reconheceu a LIBRAS como a segunda língua oficial no país e determinou que fosse criada a disciplina de LIBRAS na universidade. Tal como consta no capítulo II do referido decreto:

Art. $3^{-}$A Libras deve ser inserida como disciplina curricular obrigatória nos cursos de formação de professores para o exercício do magistério, em nível médio e superior, e nos cursos de Fonoaudiologia, de instituições de ensino, públicas e privadas, do sistema federal de ensino e dos sistemas de ensino dos Estados, do Distrito Federal e dos Municípios.

$1^{\underline{0}}$ Todos os cursos de licenciatura, nas diferentes áreas do conhecimento, o curso normal de nível médio, o curso normal superior, o curso de Pedagogia e o curso de Educação Especial são considerados cursos de formação de professores e profissionais da educação para o exercício do magistério.

$\S 2^{\circ}$ A Libras constituir-se-á em disciplina curricular optativa nos demais cursos de educação superior e na educação profissional, a partir de um ano da publicação deste Decreto. (BRASIL, 2005).

Work. pap. linguíst., 13(3): 79-86, Florianópolis, out.dez,2012 
A introdução da disciplina de LIBRAS acarretou diferentes recepções sobre a criação e a obrigatoriedade para alunos de licenciatura e pedagogia. É isso que este artigo colocará por meio de reflexões: como a LIBRAS é observada, aprendida e utilizada pelos graduandos que por muitas vezes nunca antes tiveram contato com a língua de sinais.

A disciplina de LIBRAS se relaciona com o contexto real e diário na sala de aula; com metodologias de ensino do aluno surdo; com as disciplinas comunicativas; com o despreparo do corpo docente, seja na escola ou na universidade. Este artigo, por meio do que se observa no decorrer da disciplina, relatará a realidade em sala de aula, a realidade social e acadêmica gerada pela inclusão da LIBRAS como disciplina obrigatória.

\section{QUESTÕES SOBRE O ENSINO DA LIBRAS NAS UNIVERSIDADES}

Alguns pontos que se observam pelas questões apresentadas aqui é a dificuldade da presença de intérpretes, a falta de material didático específico, os discentes e a universidade com pouca ou nada de informação, os professores desmotivados, as inquietações sobre o processo de avaliação dos discentes, as conquistas de valorização do papel do professor de LIBRAS, as mudanças na universidade em relação a quem é e como interagir com o surdo (sendo esse professor ou aluno), entre outros fatores.

Deseja-se, assim, expor o cotidiano vivido pelo professor de LIBRAS, sua metodologia de ensino em tentativa diária de ensinar o respeito e a valorização da língua de sinais, uma vez que serão eles que estarão em contato diário com os alunos surdos nas escolas, nas universidades e no próprio cotidiano.

\subsection{ATITUDES EM RELAÇÃO AOS SURDOS E À LIBRAS}

Ter a disciplina de LIBRAS nas universidades brasileiras é uma aquisição extremamente importante para a comunidade surda. É como um troféu conquistado arduamente pelos surdos durante anos de luta pela valorização da língua de sinais. Luta que corresponde a um passo no meio de todo caminho percorrido e a ser percorrido. Caminho que não acabou e continua no cotidiano enfrentado e vivido pelo surdo.

Ter a língua de sinais no currículo da universidade não gera uma mudança social somente por essa presença. Somente se os alunos entenderem e aceitarem a língua de sinais é que teremos uma modificação social. É o caso de alunos que já trabalham como professores e que já tiveram a experiência em sala de aula com um aluno surdo. Este graduando terá uma melhor receptividade da LIBRAS do que o aluno que nunca teve contato antes. (ROSA, 2010, p. 315)

Fala-se sobre a língua de sinais e sua disciplina, mas ainda não há entendimento sobre surdo; este é, por vezes, visto como "deficiente" pela sociedade que foca o patológico ao invés do linguístico. Mesmo com a existência da LIBRAS, ainda há desconhecimento sobre todo o contexto em que essa língua se insere. A divulgação está acontecendo aos poucos por meio da mídia, palestras, cursos de formação e inclusive dentro da universidade por meio da disciplina língua de sinais. A lei e o Decreto de LIBRAS não finda a preocupação da educação e do desenvolvimento social dos surdos;

Work. pap. linguíst., 13(3): 79-86, Florianópolis, out.dez,2012 


\section{http://dx.doi.org/10.5007/1984-8420.2012v13n3p79}

O governo acredita efetivar a inclusão social e educacional a partir da disciplina, a qual teria função de capacitar os futuros profissionais que fossem lecionar a surdos. Não foi levado em consideração que para ser fluente em LIBRAS, e assim lecionar adequadamente a esse grupo de alunos, é necessário anos de curso e convivência com os surdos, pois a língua de sinais é complexa e tem o mesmo status e dificuldade de aprendizagem e compreensão de qualquer língua oral.

\subsection{FORMAÇÃO E PERFIL DOS PROFESSORES DE LIBRAS}

O professor de língua de sinais deve ser visto como qualquer outro professor, capaz de educar, influenciar e estimular seus alunos nas descobertas linguísticas de uma língua naturalmente visuoespacial e motivadora da possibilidade de interagir com o outro e o mundo em que se vive.

Atualmente observa-se que o cargo de professor de LIBRAS pode ser ocupado por surdos ou ouvintes. Em algumas universidades, exigem que o professor seja formado e/ou tenha pós-graduação, mestrado ou doutorado, ou seja, é necessário que tal professor tenha titulação, formação e fluência para lecionar a língua de sinais.

(...) Para que o docente consiga lidar com todos os fatores que se articula em sua prática, tem que estar bem preparado, o que nos conduz a uma problemática recorrente: a formação do educador - que, para alcançar os resultados pretendidos, nunca pode ser dada como concluída. (GOMES, 2003, p.51)

Pensa-se no professor, mas junto a isso devemos observar o ambiente em que ele leciona. Por vezes algumas universidades, quando o professor surdo solicita o ILS (intérprete de língua de sinais), não dispõem ou não contratam esse profissional por questões financeiras e ou burocráticas. O ILS é um profissional capacitado e fluente para interpretar língua de sinais/português/língua de sinais sempre que o professor surdo necessitar. Caso esse professor não disponha do ILS, ele deve se preocupar em conversar com alunos, direção da universidade, ou deve só "trabalhar" sem ser ouvido? É preciso lembrar que muitos no meio acadêmico não possuem conhecimentos da língua de sinais dificultando, assim, a conversação surdo/ouvinte.

Da mesma forma que há professores surdos fluentes no ensino da língua de sinais em algumas universidades, há também professores ouvintes não fluentes em LIBRAS que dão aula teórica para os alunos e depois convidam o outro professor surdo para dar aula prática. Alguns desses professores não fluentes não convivem com a comunidade surda, não disponibilizando a prática da língua de sinais, peça fundamental da disciplina de LIBRAS. Atenta-se que a convivência com a comunidade surda é fundamental, pois a língua de sinais também tem suas alterações, inovações assim como a língua oral.

A existência do PROLIBRAS (certificação de proficiência em Língua de Sinais para uso e ensino) é um fator que merece cuidado. Tal certificação foi criada em vista da necessidade de provar que os profissionais sabiam a língua de sinais para assim tomar posse como professor na disciplina de LIBRAS. Ter o certificado não quer dizer que a pessoa seja fluente, ela pode ter treinado o necessário para ser aprovada e ter esse certificado; o que acontece com vários ouvintes que desejam ser professores de língua de sinais, mas não possuem fluência, isso porque muitos concursos pedem no edital o certificado do PROLIBRAS. Sobre o PROLIBRAS tem-se:

Work. pap. linguíst., 13(3): 79-86, Florianópolis, out.dez,2012 


\section{http://dx.doi.org/10.5007/1984-8420.2012v13n3p79}

Em relação aos exames de proficiência, estes foram uma medida federal emergencial, adotada pelo Ministério da Educação, para que as instituições de ensino superior se adequassem aos prazos da lei, enquanto os primeiros graduandos em Letras Libras Licenciatura e pós-graduandos em LIBRAS concluíssem seus cursos, uma vez que o primeiro prazo estabelecido pelo Decreto para inclusão da disciplina de LIBRAS, expirou antes da formação desses professores. Ou seja, o prazo mínimo estabelecido para viabilização da inclusão da LIBRAS como disciplina se adiantou ao prazo necessário para formação de profissionais habilitados para essa docência. (SIMPLÍCIO, 2009)

Sendo assim, é importante ressaltar que não será somente um certificado que dará ao profissional a capacidade de lecionar uma língua, mas sim a fluência e conhecimentos sobre ela, além de ter perfil como professor.

\subsection{CARACTERÍSTICAS DOS ALUNOS E DAS TURMAS DE AULA}

Não adianta mostrar somente as vivências dos professores sem apontar fatores cotidianos. Algumas situações que ocorrem nas universidades de acordo com experiências e observações são: turmas superlotadas, alunos de diferentes cursos numa mesma turma, alunos que não conseguem sinalizar por dificuldade motora ou idade ("fase de maturação vencida"1), alunos que não memorizam sinais, alunos que não usam de forma alguma expressão facial, alunos que não participam de aula expositiva por falta de interesse, vontade ou timidez de expor o corpo em movimento (através das expressões facio-corporais).

Seria o fato de que o aprendizado da língua de sinais é assim como qualquer aprendizado de uma língua, ou seja, "A aquisição da linguagem é assim um processo universal, sujeito à maturação biológica e à maturação linguística - o desenvolvimento regular e o domínio das capacidades de falar e de compreender." (PINTO, 2005)

Qualquer conteúdo, língua ou outro tipo de conhecimento quando obrigatório leva a uma desestimulação por parte dos alunos. É o que se tem na disciplina de LIBRAS na graduação quando alunos participantes das aulas não dão o máximo de si visto a falta de interesse.

\subsection{TIPOS DE AVALIAÇÃO}

O professor de língua de sinais se depara com as características dos alunos e das turmas e descobre outro problema: o da avaliação. Como seria a avaliação? Avaliam-se os conhecimentos adquiridos na parte prática e na parte teórica. Mas como avaliar um aluno com dificuldade motora ou com dificuldade de compreensão pelo fato de a língua de sinais ser de modalidade visuoespacial? Há alunos que não dominam a expressão facio-corporal (essencial para o entendimento da língua de sinais), outros não

\footnotetext{
1 Quando falamos de "maturação vencida" significa alunos com idade adulta que podem vir a ter dificuldade de armazenar novas informações de outras línguas. Esses alunos possuem dificuldade de aprender a LIBRAS, sinalizá-la ou ainda executar as expressões facio-corporais. Isso porque a maturação linguística no indivíduo "é capaz de assimilar naturalmente as regras e os princípios que regem o funcionamento dessa língua, dominando-a na forma e no uso ao fim de algum tempo. Esta faculdade pressupõe um suporte físico e estruturas mentais exclusivas da espécie humana" (PINTO, 2005).
}

Work. pap. linguíst., 13(3): 79-86, Florianópolis, out.dez,2012 
memorizam sinais, outros ainda não conseguem ao mesmo tempo o uso de sinais e de expressão facio-corporais.

São muitos os casos encontrados que limitam o desenvolvimento. O aluno deverá ser reprovado? Nem sempre. Reprovar alunos mais idosos e/ou com maturação vencida é complicado visto o limite físico. Reprovar adianta? Novamente, nem sempre. Alunos que fazem novamente a disciplina por conta de reprovação não mostram melhorias. Em alguns casos, em cursos de extensão, capacitação ou mesmo como disciplina curricular de universidade, o aluno não poderá ser reprovado mesmo tendo parco desenvolvimento em LIBRAS.

São muitas dúvidas, muitas questões sem resposta confiante. Cada professor leva em conta muitas coisas na hora de avaliar. Há os que avaliam pela participação e desenvolvimento durante a rotina de aulas, há os que dão provas e outros trabalhos a serem apresentados. Há os que avaliam pelo limite e esforço em aprender dos alunos em sala de aula. Muitas formas para o mesmo objetivo: estimular o contínuo conhecimento dos alunos na língua de sinais.

\subsection{OBJETIVOS DE ENSINO}

Refletindo sobre essas situações, obtêm-se outras indagações. É preciso pensar no currículo de LIBRAS e os conteúdos; se o professor deveria ensinar em num só semestre somente o básico geral ou com foco na área dos alunos ou ainda quais as teorias a serem estudadas. É preciso novamente lembrar que muitas vezes a sala de aula é composta de alunos de diferentes cursos e não se pode centrar num único curso ou conteúdo.

Sobre isso Benedetti fala sobre o ensino de LIBRAS em um curso superior, no caso matemática, que mesmo assim seria importante o aluno aprender o curso básico a fim de um melhor aprendizado dos conteúdos:

O professor da disciplina deve identificar o aluno surdo observando as características que apresenta. Demonstrar conhecimentos sobre a metodologia do ensino para o surdo. Comunicar-se com o surdo. Dominar os aspectos linguísticos da Língua Brasileira de Sinais, como a fonologia, a morfologia e a sintaxe além de discutir o papel social da educação inclusiva. (BENEDETTI, 2009)

$\mathrm{Na}$ parte teórica, deve-se apresentar sobre a introdução a LIBRAS, cultura e comunidade surda e, fundamentalmente, sobre os surdos. Teorias são necessárias para o entendimento do funcionamento da língua e seus usos. A aula de língua de sinais não corresponde somente à prática, sinais soltos ou expressões. A teoria é essencial para que o alunado entenda o motivo de cursar essa disciplina, além de perceber o que a sociedade mostra como 'verdade absoluta' e a realidade da comunidade surda. O aluno, a partir de então, se conscientizará da existência e da necessidade da LIBRAS no meio acadêmico e sócio-educacional.

Em se tratando da presença da disciplina no currículo acadêmico, mais semestres letivos dessa disciplina poderiam existir para um maior aproveitamento. Entretanto algumas universidades, ou ainda alguns professores, não vêem essa possibilidade por questões burocráticas, financeiras, de falta de profissionais, de legitimidade da língua de sinais e de sua importância para as universidades (sim, mesmo com lei e decreto ainda há pessoas nas universidades, e fora dela, que vêem a língua de sinais sem o mesmo valor linguístico da língua oral), entre tantos outros fatores.

Work. pap. linguíst., 13(3): 79-86, Florianópolis, out.dez,2012 


\section{http://dx.doi.org/10.5007/1984-8420.2012v13n3p79}

Toda essa fundamentação é necessária para que se tenha desenvolvimento e interação na disciplina tanto no curso de graduação quanto no possível uso da língua de sinais no cotidiano. Em se tratando da aceitação do corpo docente, é preciso, acima de metodologias ou ensinamentos, a compreensão de que a disciplina de LIBRAS se relaciona com o contexto real e diário na sala de aula e da própria sociedade.

\section{CONCLUSÃO}

Conclui-se que não basta inserir via lei uma disciplina buscando melhorias na educação dos surdos, se essa mesma disciplina não possui meios para sua própria melhoria. Sim, é de extrema importância a existência do ensino de língua de sinais na graduação, assim como é essencial que se tenha formas para seu desenvolvimento e propagação.

Realmente, pensando no que foi lido neste texto, há questões a serem resolvidas, observações e dificuldades. O que pode ser feito para melhorar a situação é um consenso entre professores de modo que haja uma equivalência do que vai ser ensinado, como e por quê; dando ênfase ao que é essencial. Se o tempo é curto para tanta coisa, é preciso pensar e lecionar conscientemente. Assim como observar as características dos alunos, suas dificuldades e limites e tentar um meio de avaliar sem perda, o que é difícil, mas não impossível.

Com desafios e necessidades todos se deparam diariamente na sala de aula, o que muda é a forma como são observados, vivenciados e solucionados. Isso porque "a sala de aula é um ponto de encontro das diferentes histórias, dos diferentes percursos, dos diferentes saberes (...)" (SMOLKA, 1989, p. 41).

Sendo assim, esse é o conhecimento ou reflexão do que seria o ensino da língua de sinais na graduação e o papel do professor de LIBRAS. Há a necessidade de que as universidades e o governo repensem e acatem as propostas e reivindicações do surdo para que a inclusão se efetive de forma mais justa, harmônica e consciente. Deve-se entender a "revolta" e indagações do professor de língua de sinais perante a proposta de inclusão "largada" de qualquer jeito só para cumprir a lei.

O professor deve se deixar seguir ao sabor do vento, mas mantendo raízes no que acredita; raízes fortes e solidificadas que reconhece a terra na qual se está e que reconhece o momento certo de deixar o mesmo vento levar sementes e semear outros campos, alguns ainda rígidos, secos, mas que o próprio vento se encarrega de, junto a outros elementos, semear, adubar e irrigar. (ROSA, 2009, p. 154)

É necessário observar que o professor de língua de sinais já em sala de aula vivencia o que foi exposto neste artigo e tenta de todas as formas equilibrar-se entre o que possui, o que pretende e o que lhe vem ao encontro. Apesar do ensino enfrentar uma série de problemas que envolvem questões burocráticas, políticas, sociais e linguísticas, os referidos professores tendem a criar possibilidades para superar as dificuldades e lecionar a referida disciplina, buscando encaminhamentos para que $o$ ensino dessa língua seja incorporado nas universidades com qualidade.

Work. pap. linguíst., 13(3): 79-86, Florianópolis, out.dez,2012 
http://dx.doi.org/10.5007/1984-8420.2012v13n3p79

\section{REFERÊNCIAS}

BENEDETTI, Luis Antonio. A disciplina LIBRAS no currículo do curso de Licenciatura em Matemática. In: FAMAT em Revista. Uberlândia: UFU, 2009.

Disponível em:

http://www.portal.famat.ufu.br/sites/famat.ufu.br/files/Anexos/Bookpage/famat revista 13 reflexoes.pdf. Acesso em: julho de 2011.

BRASIL. Lei $n^{\circ} 10.436$ de 24 de abril de 2002, que dispõe sobre a Língua Brasileira de Sinais - LIBRAS e dá outras providências. Disponível em: http://www.planalto.gov.br/ccivil 03/Leis/2002/L10436.htm. Acesso em 10 de out de 2012.

BRASIL. Decreto $n^{\circ} 5.626$, de 22 de dezembro de 2005, que regulamenta a Lei $n^{\circ}$ 10.436. Disponível em: http://www.planalto.gov.br/ccivil 03/ ato20042006/2005/decreto/d5626.htm. Acesso em 10 de maio de 2010.

GIORDANI, Lilianae. Educação inclusiva na educação de surdos: o que se permite entre a política oficial e o movimento social? In: VIEIRA-MACHADO, Lucyenne \& LOPES, Maura (org.). Educação de surdos. Políticas, língua de sinais, comunidade e cultura surda. Santa Cruz do Sul: EDUNISC, 2010.

GOMES, Márcia P. R. de Magalhães. A Importância da Relação Professor- Aluno na Construção do Conhecimento. In: Espaço: Informativo Técnico- Científico do Instituto Nacional de Educação de Surdos (INES). Rio de Janeiro: INES, 2003. n ${ }^{\circ} 20$ (dez/2003), p.50-4.

PINTO. Claudia. Definição de maturação linguística. Disponível em: http://www.flip.pt/language/en-US/Duvidas-Linguisticas/Duvida-

Linguistica/DID/1172.aspx. Acesso em: julho de 2011.

ROSA, Emiliana Faria. Professor surdo e meio acadêmico: a vida presente no tempo presente. In: Anais do VI congresso internacional de educação. São Leopoldo: UNISINOS, 2009.

LIBRAS na universidade: mudança de currículo, mudança na sociedade? In: Anais do SENALE. Pelotas: UCPEL, 2010.

SIMPLÍCIO, Valéria. O professor de libras - língua brasileira de sinais nas séries finais do ensino fundamental, no ensino médio e no ensino superior: formação $x$ habilitação. Publicado em 2009. Disponível em: http://www.webartigos.com/articles/27832/1/O-PROFESSOR-DE-LIBRAS--LINGUA-BRASILEIRA-DE-SINAIS-NAS-SERIES-FINAIS-DO-ENSINOFUNDAMENTAL-NO-ENSINO-MEDIO-E-NO-ENSINO-SUPERIOR-FORMACAOx-HABILITACAO/pagina1.html\#ixzz1SZN2rm4a. Acesso em: julho de 2011.

SMOLKA, Ana Luiza Bustamante. O Trabalho Pedagógico na Diversidade (Adversidade?) da Sala de Aula. In: Cadernos CEDES. São Paulo: Cortez, 1989. n 23, p.39-47.

Work. pap. linguíst., 13(3): 79-86, Florianópolis, out.dez,2012 